\title{
Interpreting Umbilical Cord Blood Gases: Cord Occlusion with Terminal Fetal Bradycardia: Part II
}

Jeffrey Pomerance, MD, MPH

\section{Case 10: Umbilical Cord Occlusion with Terminal Fetal Bra- dycardia, Mild}

The mother was a 26-year-old, gravida 4, para 3, aborta 0 , with an intrauterine pregnancy at 40 0/7 weeks' gestation by good dates. Because of decreased fetal movement complaint three days before admission, a non-stress test was performed and was reactive, but had several mild, variable decelerations. Membranes ruptured spontaneously two hours prior to admission. During labor, the FHR monitor revealed recurrent variable decelerations that were deeper and longer-lasting, and then a deceleration to 60 $\mathrm{bpm}$ for three minutes. The patient was taken fully dilated to the delivery room, where the FHR monitor revealed a variable deceleration to $60 \mathrm{bpm}$ for 90 seconds. The infant was then delivered by outlet forceps. The umbilical cord was tight around the shoulder and body. Apgar scores were 6 and 9 at one and five minutes, respectively.

Cord blood gas results were as follows:

\begin{tabular}{|l|l|l|}
\hline & Umbilical Vein & $\begin{array}{l}\text { Umbilical } \\
\text { Artery }\end{array}$ \\
\hline $\mathbf{p H}$ & 7.22 & 7.10 \\
\hline $\begin{aligned} \mathrm{Pco}_{2}(\mathbf{m m H g}) \\
(\mathbf{k P a})\end{aligned}$ & 52 & 70 \\
\hline $\begin{array}{r}\mathrm{Po}_{2}(\mathbf{m m H g}) \\
(\mathbf{k P a})\end{array}$ & 6.93 & 9.33 \\
\hline $\mathrm{BD}(\mathbf{m m o l} / \mathbf{L})$ & 18 & 10 \\
\hline
\end{tabular}

\section{Interpretation}

The respiratory acidosis in the venous sample is mild; the base deficit is within normal limits. The respiratory acidosis in the arterial sample is also mild, but there is also a mild metabolic acidosis. The usual relationship between venous and arterial values is intact; the venous $\mathrm{pH}$ and $\mathrm{PO}_{2}$ are higher, and the venous $\mathrm{PCO}_{2}$ is lower. However, the differences between venous and arterial $\mathrm{pH}, \mathrm{PCO}_{2}$, and base deficit are greater than usual. The hallmark of cord occlusion with terminal bradycardia is widened venoarterial $\mathrm{pH}, \mathrm{PCO}_{2}$, and sometimes base deficit differences, usually associated with normal or near-normal umbilical venous cord gases.

Widened differences also may be associated with fetal heart failure. With intact umbilical-placental circulation, any metabolic acidosis appearing in the umbilical artery will almost instantaneously appear in the umbilical vein. However, because lactic acid crosses the placenta poorly, a greater base deficit in the arterial cord blood sample indicates the presence of umbilical vein occlusion with at least some interval of partially restored umbilical arterial blood flow. There is no general agreement on the definition of a widened base deficit difference. However, it seems safe to assume that a difference of $4 \mathrm{mmol} / \mathrm{L}$ or more is significant.

Because $\mathrm{pH}$ is the most reproducible of the three measured blood gas parameters, looking at the difference between $\mathrm{pHs}$ to alert to an abnormally large difference is most helpful. Using the data published by Yeomans, Hauth, Gilstrap, and Strickland, the average $\mathrm{pH}$ difference is 0.07 (7.35 minus $7.28=0.07)$. Assuming a normal distribution of differences between umbilical venous and arterial $\mathrm{pH}$, the upper limit of the $95^{\text {th }}$ percentile range is 0.10 (see Case 5). Finding a pH difference greater than 0.10 suggests either cord occlusion with terminal bradycardia or chronic fetal heart failure with terminal bradycardia. The former is a much more common event. Likewise, any umbilical venoarterial $\mathrm{PCO}_{2}$ difference of greater than $18 \mathrm{mmHg}$ also is associated with either cord occlusion with terminal fetal bradycardia or chronic fetal heart failure with terminal fetal bradycardia. Although widened $\mathrm{pH}$ differences are almost always associated with cord occlusion with terminal fetal bradycardia, rarely the $\mathrm{pH}$ difference falls within the normal range, $0.04-0.10$. A widened difference in $\mathrm{PCO}_{2}(18 \mathrm{mmHg}$ or greater) in the absence of a widened $\mathrm{pH}$ difference is clinically quite rare.

The umbilical vein is more easily compressed than the umbilical arteries because it has a thinner muscular wall, and the mean blood pressure in the vein is lower than that in the arteries by a factor of approximately ten. At term, normal mean umbilical venous blood pressure is $4.9 \mathrm{mmHg}$, whereas normal mean aortic blood pressure is about $52 \mathrm{mmHg}$. Although these arterial blood pressure measurements were taken in fetal sheep, they are thought to be a reasonable estimate for the human fetus.

As the umbilical cord is compressed, blood flow in the umbilical vein may briefly slow prior to coming to a complete stop. Johnson and Richards have reported that in cases of umbilical cord prolapse, umbilical venous $\mathrm{PO}_{2}$, oxygen saturation, and oxygen content were all significantly greater than reference values. This makes good sense if there is a period of time preceding total venous occlusion when the blood in the umbilical vein is slowed rather than halted. The slower the circulation is through the placenta, the greater the amount of oxygen diffusion from mother to fetus, and the higher the $\mathrm{PO}_{2}$ in the umbilical vein. Additionally, in the face of FHR decelerations, the mother is usually administered supplemental oxygen, which may also be expected to raise the umbilical venous $\mathrm{PO}_{2}$, as long as there is continued umbilical venous blood flow.

Benirschke and Kaufman have observed that cord compression (presumably cord occlusion followed by terminal fetal bradycardia) leads to congestion in the terminal capillaries and an increase in villous blood volume, sometimes by more than $50 \%$. One might use this estimate to calculate the maximum amount of blood a fe- 


\section{Cord Occlusion with Terminal Fetal Bradycardia}

Anatomy and Pathophysiology:

Sequential Events and Approximate Timeline

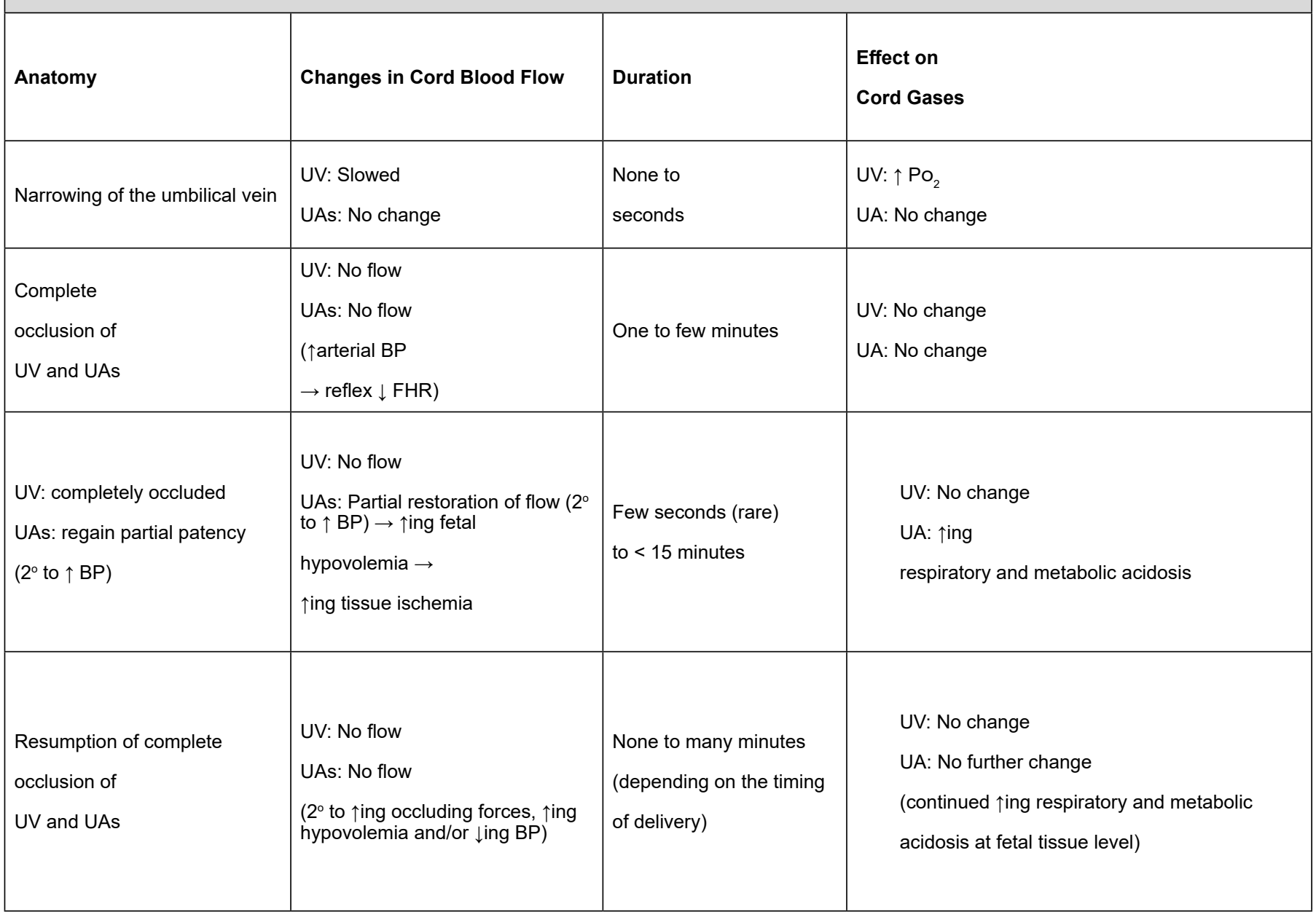

\section{Table}

Cord occlusion with terminal fetal bradycardia: Relationship of anatomy, pathophysiology, duration, and effect on umbilical cord blood gases.

UV, umbilical vein; UAs, umbilical arteries; $\uparrow$, increased; $\downarrow$, decreased; $2^{\circ}$, secondary

tus could transfer to the placenta during cord occlusion associated with terminal fetal bradycardia. Then using $125 \mathrm{~mL} / \mathrm{kg}$, of newborn weight as the total fetal-placenta blood volume and $84 \mathrm{~mL} / \mathrm{kg}$ as the total blood volume of a term newborn, one could calculate the approximate upper end of blood transferred from fetus to placenta, i.e., a placental blood volume increase of approximately $20.5 \mathrm{~mL} / \mathrm{kg}$ (50\% of placenta blood volume: 125 minus $84 \mathrm{~mL} / \mathrm{kg}$ $=41 \mathrm{~mL} / \mathrm{kg}$ times $50 \%=20.5 \mathrm{~mL} / \mathrm{kg}$, divided by $84 \mathrm{~mL} / \mathrm{kg}=24 \%$ ), giving an approximate maximum transfer of $24 \%$ of the total fetal blood volume.

Clearly, $\mathrm{PO}_{2}$ is not always elevated following cord occlusion with terminal bradycardia. At times, congestion might lead to a decreased efficiency of the transfer of carbon dioxide and oxygen between mother and fetus.

The $\mathrm{pH}, \mathrm{PCO}_{2}$ and base deficit change quite slowly in a completely occluded umbilical vessel, likely because much of the surrounding tissue (Wharton's jelly) has very little metabolic activity and accordingly utilizes very little oxygen and produces very little carbon dioxide. Meanwhile, the fetus is being deprived of its only supply of oxygen and has a gradually decreasing blood volume. This results in progressive deterioration of the blood gas in the umbilical arteries as long as blood continues to flow in these vessels. If cord occlusion occurs intermittently prior to a terminal cord occlusion and bradycardia, as is usually the case, any respiratory or metabolic acidosis in the fetus will likely recover completely between episodes. If the episodes are severe enough or frequent enough, there may be insufficient time for complete recovery between episodes, and acid-base values will deteriorate over time. In the experimental animal, it has been demonstrated that occluding the cord for one minute and repeating the occlusion every 2.5 minutes results in progressive acidosis in the fetus.

The most likely pathophysiology is as follows: Initially, in terminal cord occlusion, both the umbilical vein and the umbilical arteries are occluded. Usually, however, the blood flow in the umbilical arteries is restored temporarily due to increasing fetal blood pressure. Because of increasing occluding forces, or as fetal blood 
pressure begins to falter secondary to fetal hypovolemia and cardiac hypoxia, the fetus' ability to continue umbilical artery blood flow will end. When blood flow ceases in the umbilical arteries, the umbilical arterial blood gas will only reflect the fetal blood gas status at the time blood stopped flowing (see Table above).

\section{"The most likely pathophysiology is as follows: Initially, in terminal cord occlusion, both the umbilical vein and the umbilical arteries are occluded. Usually, however, the blood flow in the umbilical arteries is restored temporarily due to increasing fetal blood pressure."}

Differences between umbilical venous and arterial samples can become very wide (see next installment). Wider differences suggest a longer interval of umbilical vein obstruction with the restored umbilical arterial flow and greater fetal hypovolemia. The time-volume relationship has not yet been quantified, but the duration of umbilical arterial blood flow in the absence of venous return is likely to vary from just a minute or two to probably not more than 10-15 minutes in the extreme. To my knowledge, all animal studies of fetal cord occlusion involve sudden and complete occlusion rather than any period of continued venous occlusion with the restored arterial flow.

Volume expansion is encouraged as part of advanced neonatal resuscitation if more basic care does not result in the desired improvement. However, there is no clear evidence that volume expansion is helpful in neonatal asphyxia. This is difficult to study because of the rarity of delivery room resuscitation that includes volume expansion. As far as I am aware, cord occlusion with terminal bradycardia has never been studied separately as a cause of neonatal asphyxia. It is these infants who are most likely to benefit from volume expansion. As one erudite neonatologist summarized, "Just add water!" (saline).

Although uncommon, the venous sample also may demonstrate significant respiratory and metabolic acidosis. Of course, terminal cord occlusion does not preclude severe repetitive cord occlusion with insufficient time for even the $\mathrm{PCO}_{2}$ to fully recover between occlusive episodes or a preexisting or simultaneous occurrence of uteroplacental insufficiency.

As previously discussed, when uteroplacental insufficiency causes fetal metabolic acidosis, the degree of metabolic acidosis is approximately the same in both umbilical venous and arterial samples. However, when umbilical cord occlusion associated with terminal bradycardia is the underlying pathology, the umbilical artery sample typically has a worse base deficit than in the umbilical vein sample.' In the current case, the difference in the degree of metabolic acidosis between venous and arterial samples is not great (BD $7 \mathrm{mmol} / \mathrm{L}$ versus 11). A difference between base deficits of four or more should suggest umbilical cord occlusion with terminal fetal bradycardia (or much more rarely, fetal heart failure). Once terminal fetal bradycardia has begun, the umbilical venous blood flow does not reopen; therefore, the venous sample is usually a reasonable proxy for the infant's acid-base status prior to terminal fetal bradycardia.

\section{"Once terminal fetal bradycardia has begun, the umbilical venous blood flow does not reopen; therefore, the venous sample is usually a reasonable proxy for the infant's acid-base status prior to terminal fetal bradycardia."}

\section{Key Points}

- $\quad$ The umbilical vein is much easier to occlude than the umbilical arteries.

- $\quad$ Prior to total cord occlusion, there may be a brief period of slowed umbilical venous blood flow. When this occurs, one should expect a higher $\mathrm{PO}_{2}$, as increased transit time will result in more time for oxygen to download across the placenta.

- With an intact umbilical-placental circulation, any metabolic acidosis appearing in the umbilical arteries will almost instantaneously appear in the umbilical vein. However, because lactic acid crosses the placenta relatively poorly, a significantly greater base deficit in arterial cord blood indicates the presence of umbilical vein occlusion with at least some interval of partially restored umbilical arterial blood flow.

- $\quad$ Once the umbilical vein becomes occluded, a blood gas sample will only reflect the status prior to the occlusion.

- The hallmark of cord occlusion with terminal bradycardia is widened venoarterial $\mathrm{pH}, \mathrm{PCO}_{2}$, and sometimes base deficit differences, and is usually associated with a normal or nearnormal umbilical venous cord gas.

- A difference between umbilical venous and arterial pHs greater than 0.10 is suggestive of cord occlusion with terminal bradycardia.

- Wider than normal differences between umbilical venous and arterial $\mathrm{pH}, \mathrm{PCO}_{2}$, and sometimes base deficit suggest an interval when the umbilical vein was occluded, but the blood flow in the umbilical arteries had been restored.

- $\quad$ The wider the differences between umbilical venous and arterial samples, likely the longer the interval of umbilical vein obstruction with the restored umbilical arterial flow. Likewise, there will also be a greater associated fetal hypovolemia.

\section{References:}

1. Pomerance J. Umbilical cord blood gas casebook: Interpreting umbilical cord blood gases, Part V. J Perinat 1999;19:466-7.

2. Blechner JN. Maternal-fetal acid-base physiology. Clin Obstet Gynecol 1993;36:3-12.

3. Yeomans ER, Hauth JC, Gilstrap LC III, Strickland DM. Umbilical cord pH, PCO2, and bicarbonate following uncomplicated term vaginal deliveries. Am J Obstet Gynecol 1985; 151:798-800.

4. Bear M. Personal communication, 2011.

5. Edwards AL. Experimental design in psychological research, 4th ed. New York, Holt Rinehart Winston; 1972, p274-5.

6. Okamura K, Murotsuki J, Kobayashi M, Yano M, et al. Umbilical venous pressure and Doppler flow pattern of inferior vena cava in the fetus. Am J Perinatol 1994;11:255-9.

7. Teitel DF, Iwamoto HS, Rudolph AM. Effects of birth- 
related events on central blood flow patterns. Pediatr Res 1987;22:557-66.

8. Johnson JWC, Richards DS. The etiology of fetal acidosis as determined by umbilical cord acid-base studies. Am J Obstet Gynecol 1997;177:274-81.

9. Edelstone DI, Peticca BB, Goldblum LJ. Effects of maternal oxygen administration on fetal oxygenation during reductions in umbilical blood flow in fetal lambs. Am J Obstet Gynecol 1985;152:351-8.

10. Haruta M, Funato T, Sumida T, Shinkai T. The influence of oxygen inhalation for 30 to 60 minutes on fetal oxygenation. Nippon Sanka Fujinka Gakkai Zasshi 1984;36:1921-9.

11. Benirschke K, Kaufman P. Architecture of normal villous trees, In: Pathology of the Human Placenta, 2nd edition. New York, Springer-Verlag; 1990, p91.

12. Usher R, Shephard M, Lind J. The blood volume of the newborn infant and placental transfusion. Acta Paediatr 1963;52: 497-512.

13. Gruenwald P. Growth of the human foetus. In: McLaren A (ed): Advances in reproductive physiology. New York, Academic Press, 1967, p279.

14. Price DC, Ries C. Hematology. In: Handmaker H, Lowenstein JM (eds): Nuclear medicine in clinical pediatrics.. New York, Society of Nuclear Medicine, 1975, pp167-185.

15. Dunn PM. Tight nuchal cord and neonatal hypovolemic shock. Arch Dis Child 1988;63:570-1.

16. Vanhaesebrouck $P$, Vanneste $K$, de Praeter $C$, van Trappen $Y$. Tight nuchal cord and neonatal hypovolemic shock. Arch Dis Child 1987;62:1276-7.

17. Westgate JA, Bennett L, Gunn AJ. Fetal heart rate variability changes during brief repeated umbilical cord occlusion in near term fetal sheep. Br J Obstet Gynaecol 1999;106:664-71.

18. American Academy of Pediatrics: Textbook of Neonatal Resuscitation, 7th ed. 2016, Medications.

19. Wyckoff MH, Perlman JM, Laptook AR. Use of volume expansion during delivery room resuscitation in near-term and term infants. Pediatrics 2005;115:950-5.

20. Wykoff M, Garcia D, Margraf L, Perlman J, et al. Randomized trial of volume infusion during resuscitation of asphyxiated neonatal piglets. Pediatr Res 2007;61:415-20.

21. Boggs S, personal communication, 2012.

22. Khazin AF, Hon EH, Yeh SY. Observations on fetal heart rate and fetal biochemistry - III: Base deficit of umbilical cord blood. J Pediatr 1971;79:406-12.

23. Martin GC, Green RS, Holtzman IR. Acidosis with nuchal cords and normal Apgar scores. J Perinatol 2005;25:162-5.

Disclosure: The author has no disclosures.

NT

Corresponding Author
Jeffrey Pomerance, MD
Emeritus Professor of Pediatrics,
UCLA
Former Director of Neonatology,
Cedars-Sinai Medical Center, Los Angeles
Jeffrey Pomerance <ipomerance@msn.com>

\section{OPIOIDS and NAS}

When reporting on mothers, babies,

and substance use

\section{LANGUAGE MATTERS}

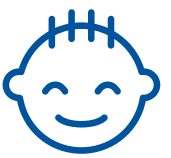

I am not an addict.

I was exposed to substances in utero. I am not addicted. Addiction is a set of behaviors associated with having a Substance Use Disorder (SUD).

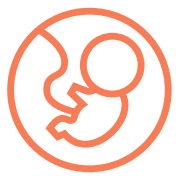

\section{I was exposed to opioids.}

While I was in the womb my mother and I shared a blood supply. I was exposed to the medications and substances she used. I may have become physiologically dependent on some of those substances.

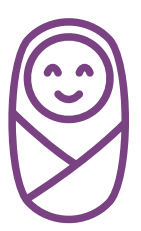

\section{NAS is a temporary and treatable condition.}

There are evidence-based pharmacological and non-pharmacological treatments for Neonatal Abstinence Syndrome.

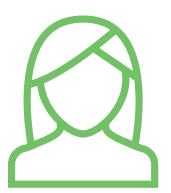

\section{My mother may have a SUD.}

She might be receiving Medication-Assisted Treatment (MAT). My NAS may be a side effect of her appropriate medical care. It is not evidence of abuse or mistreatment.

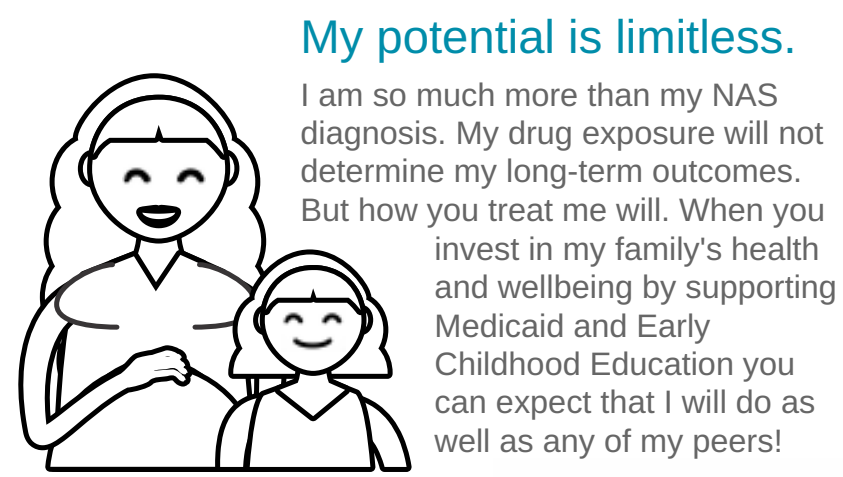

Learn more about

Neonatal Abstinence Syndrome at www.nationalperinatal.org

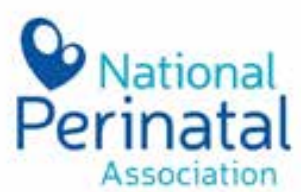

